\title{
CHRONIC AND INTERMITTENT EXPOSURE TO ALCOHOL VAPORS: A NEW MODEL OF ALCOHOL-INDUCED OSTEOPENIA IN THE RAT
}

Delphine B Maurel ${ }^{1}$, Christelle Jaffré ${ }^{1}$, Emmanuelle Simon O’Brien ${ }^{2}$, Carine C Tournier ${ }^{1}$, Hakim Houchi $^{2}$, Claude-Laurent Benhamou ${ }^{1}$, Mickael Naassila ${ }^{2}$.

\footnotetext{
${ }^{1}$ Unité Inserm U658, Caractérisation du tissu osseux par imagerie : techniques et applications, Hôpital Porte Madeleine, 1 rue porte madeleine, 45032 Orléans, France.

${ }^{2}$ Inserm ERI-24, Groupe de Recherche sur l'Alcool \& les Pharmacodépendances (GRAP),

Université de Picardie Jules Verne, SFR CAP Santé, UFR de Pharmacie, 1 rue des Louvels, 80000 Amiens, France.
}

Corresponding author : Mickael Naassila

Inserm ERI-24, Groupe de Recherche sur l'Alcool \& les Pharmacodépendances (GRAP), Université de Picardie Jules Verne, UFR de Pharmacie, 1 rue des Louvels, 80000 Amiens, France. Phone : +0033 322827758. E-mail : mickael.naassila@inserm.fr 


\section{ABSTRACT}

Background: Different models are used to study the effects of chronic alcohol consumption on bone tissue in the rat. However, the current models take several months to show indices of osteopenia as observed in chronic drinkers. Numerous studies have supported that chronic and intermittent exposure to ethanol vapors has predictive validity as a model of alcohol dependence in humans. However, this model has never been applied to bone research to study its effects on the parameters that define osteopenia. This was the goal of the present study in the rat.

Methods: Male Wistar rats were exposed to ethanol vapor inhalation (E, $n=6)$ or air (controls, $\mathrm{C}, \mathrm{n}=6$ ). Animals were exposed to chronic (11 weeks) and intermittent (14 h a day) ethanol vapor reaching stable BALs $(150-250 \mathrm{mg} / \mathrm{dl})$ at the end of the third week of inhalation. After the sacrifice, right and left femur and tibia were dissected free of fat and connective tissue and bone mineral density (BMD) was assessed by dual X-ray absorptiometry. The microarchitecture of the femur was studied using micro-computed tomography.

Results: The BMD of the left and right femurs and the left tibia was lower in the ethanol group compared to the control group. The bone volume fraction (BV/TV) and the bone surface density (BS/TV) were lower in the ethanol group compared to control animals. The trabecular number was lower in the ethanol group while the trabecular spacing was higher.

Conclusion: The decrease of the BMD, BV/TV and Tb.N is in the same range as what is observed in human drinkers and what is reported with other animal alcohol models (LieberDeCarli liquid diet, ethanol in the tap water). Therefore this model could be useful to study the effects of chronic alcohol consumption in the bone research field and has the advantage of controlling easily targeted BALs.

Keywords: alcoholism, animal model, bone, ethanol inhalation, osteopenia 


\section{INTRODUCTION}

Alcohol consumption affects numerous organs and tissues, such as bone. Chronic heavy alcohol consumption is one of the major causes of secondary osteoporosis in men, with hypogonadism and excessive corticosteroid use (Ebeling, 1998; Peris et al., 1995). Heavy alcohol consumption decreases the bone mineral density (BMD) (Alvisa-Negrin et al., 2009; Gonzalez-Calvin et al., 1993) and increases the fracture risk, due to a decrease of the trabecular and the cortical bone (Hogan et al., 1997; Sampson et al., 1997; Turner, 2000).

There are different procedures available to study the effects of alcohol consumption on bone in rodents (Maurel et al., 2012). Intraperitoneal (i.p.) injections and gavage are efficient methods for achieving high blood alcohol levels (BALs) (Callaci et al., 2009) but these techniques are stressful for the animals and may lead to inflammation and necrosis of tissues. It is difficult to administer alcohol with these techniques for a long period of time (several months) (Lieber et al., 1989). Another usual procedure whereby ethanol is provided is the use of a liquid diet allowing researchers to control the percentage of ethanol contained in the diet and also the amount of nutrients (Hogan et al., 1999; Sampson, 1998; Turner et al., 2001). This technique is less stressful for the animals and is used by many researchers as the risk of dehydration among the ethanol-fed rats is limited (D'Souza El-Guindy et al., 2010; Maurel et al., 2012). The drawback of employing this technique is that it does not mimic the human consumption pattern due to the fact that liquid and food are mixed (D'Souza El-Guindy et al., 2010). Other studies use a forced exposure in which only an alcohol solution is available as the only source of fluid, but rats may refrain from drinking, and therefore suffer from dehydration and achieve lower BALs (D'Souza El-Guindy et al., 2010; Lieber et al., 1989). Furthermore, the weight loss resulting may hide the direct effects of ethanol on bone, when the mechanism of action of ethanol on the skeleton is the primary aim of the study. 
For four decades a procedure of chronic intoxication by inhalation of ethanol vapors has been successfully used in rats to overcome their innate aversion for alcohol solution and induce both physical and behavioural alcohol dependence. The principle is to maintain constant blood ethanol concentrations for several hours a day in order to induce physical dependence that should develop over days or weeks. Thus this procedure is useful because it allows the experimenter to control both duration and value of the peak BALs while water and food are available ad libitum. Importantly, intermittent exposure more closely mimics the binge intake pattern in human alcoholics and, thus, provides a very good model of the development of dependence and compulsive use and relapse after periods of abstinence in human alcoholics (O'Dell et al., 2004). Chronic intermittent exposure to ethanol vapor is thus recognized as the gold standard model in the research on alcohol addiction (Naassila et al., 2000; Simon O'Brien et al., 2011; Valdez et al., 2002). It is therefore useful to test the efficacy of treatments on the excessive motivation to drink alcohol in association with dependence and relapse.

To date and to our knowledge, only one study used this protocol in the bone research field (Torricelli et al., 2007). The researchers investigated the osteoblasts from trabecular bone of rats after 7-week exposure to ethanol vapor, and found that the osteoblast proliferation rate and activity were significantly affected by alcohol exposure (Torricelli et al., 2007). However, no study has assessed the effects of chronic intermittent exposure to ethanol vapor on bone mineral density and bone microarchitecture. This was the objective of the present study in the rat.

\section{MATERIAL AND METHODS}

\section{Animals}


Twelve male Wistar rats weighing 200-250g upon arrival arrived in the animal care unit from Charles River Laboratory (L'Arbresle, France). Wistar rats is the most popular strain used in the ethanol inhalation procedure and is largely used in bone research. The animals were housed four per cages, in a light-reversed 12-hour light/dark cycle, in a temperature controlled at $21^{\circ} \mathrm{C} \pm 0.5^{\circ} \mathrm{C}$. The humidity was controlled $(55 \pm 10 \%)$ and the animals had water and food ad libitum.

\section{Ethanol Vapor Inhalation}

Six rats (E) were housed individually in standard cages, had unlimited access to water and were exposed to ethanol vapor in sealed clear plastic chambers (550 liters) (Naassila et al., 2000; Simon O'Brien et al., 2011). Ethanol vapor was generated by introducing pressured air in a $96 \%$ ethanol reservoir (60-80\% of hygrometry). Ethanol vapor concentration was gradually increased for 3 weeks in order to reach stable BALs (between 150 and $250 \mathrm{mg} / \mathrm{dl}$ ). Ethanol was evaporated for 14 hours during a day (on at $7.00 \mathrm{pm}$, off at $9.00 \mathrm{am}$ ) (O'Dell et al., 2004) for 8 weeks (Rimondini et al., 2002). Blood alcohol levels were regularly determined to permit the adjustment of ethanol vapor concentrations using an Analox AM1 Instrument analyzer (Imlab, Lille, France). Rat submitted to this chronic ethanol vapor inhalation (Ethanol group) displayed a physical dependence, shown by the appearance of somatic withdrawal signs, as previously described (O'Dell et al., 2004; Roberts et al., 2000). During the same period, six control animals (C) were placed in a separate sealed plastic chamber and exposed to a continuous flow of air.

\section{Bone density measurements}

After the sacrifice (lethal injection of pentobarbital), the right and left tibias and femurs were excised, cleared of fat and connective tissues, placed in paraformaldehyde $4 \%$ at $4{ }^{\circ} \mathrm{C}$. 
The tibia and femur bone mineral content (BMC) and BMD were measured by DXA (Discovery, Hologic, Bedford, Massachussets, USA) using a specific 'small animal body composition' mode. The exam was performed ex vivo. In order to mimic the soft tissue present in vivo, the bones were placed in a physiological saline solution during the exam. This apparatus is commonly used in small animals, and has been validated in our laboratory (Lespessailles et al., 2009; Maurel et al., 2011a).

\section{Microarchitecture of the trabecular bone}

The microarchitecture of the metaphysis of the femoral bone was analyzed by high resolution $\mu \mathrm{CT}$ (Skyscan 1072, Skyscan, Aartselaar, Belgium). We chose this subregion because it is rich in trabecular bone. The characteristics and methods used in our laboratory have previously been described (Bonnet et al., 2005). The parameters analyzed were: the bone volume fraction $(\mathrm{BV} / \mathrm{TV}, \%)$, the trabecular thickness Tb.Th $(\mathrm{mm})$, the trabecular number Tb.N (1/mm), the trabecular spacing Tb.Sp (mm) and the degree of anisotropy DA.

\section{Statistics}

Data are presented as mean \pm standard deviation $(\mathrm{SD})$ for all bone parameters. The statistical analyses were done using the Statview 1992-98 SAS software. Normal distribution (Gaussian) of the data was assessed with the Shapiro-Wilk test. Student t-tests were used when the distribution followed the normal law. Otherwise, the U Test from Mann \& Whitney was used. The statistical degree of significance was set at $\mathrm{p}<0.05$.

\section{RESULTS}


At the time of the sacrifice, BALs were around $1.8 \mathrm{~g} / \mathrm{l}$ in the ethanol group and we did not observe weight loss in the ethanol-exposed group (405 \pm 11 and $402 \pm 4 \mathrm{~g}$ in control and ethanol groups, respectively).

\section{Bone mineral content and bone mineral density}

We did not observe any difference for the bone mineral content of the right and left tibias and femurs. However, we found a lower BMD in the ethanol group compared to the control group at the left and right femurs and at the left tibia (Table 1). There was a trend for the right tibia BMD to be lower in the ethanol group $(\mathrm{p}=0.054)$.

\section{Microarchitecture of the trabecular metaphysis of the femur}

The bone volume fraction (BV/TV) was lower in the ethanol group compared to control animals (Table 2). The trabecular number was lower in the ethanol group (Figure 1). On the opposite, and logically, the trabecular spacing was increased in the ethanol group (Table 2). The trabecular thickness was not different between the groups after the protocol, as for the degree of anisotropy.

\section{DISCUSSION}

We designed this in vivo study to assess if the intermittent exposure to ethanol vapor can be relevant to study alcohol-induced osteopenia. We observed lower BMD at the tibia and the femurs in the ethanol group, as well as lower trabecular bone parameters, similar to other protocols of ethanol administration.

The BMD was lower in the femurs $(-7 \%)$ and in the tibia $(-5 \%)$ from the ethanol group compared to control animals, after intermittent exposure to ethanol vapor for 11 weeks and 
targeted BALS of $1.8 \mathrm{~g} / \mathrm{l}$. These data are consistent with the data reported in the literature. Bonnet et al. (Bonnet et al., 2006) found a $8 \%$ decrease of the femur BMD and a $10 \%$ decrease of the tibia BMD following ovariectomy in female rats. Our group displayed a $13 \%$ lower BMD at the femur in male Wistar rat following 17 weeks of alcohol treatment (alcohol in the drinking tap water, 35\% v/v and separated from the food) (Maurel et al., 2011a). Broulik et al. reported a 9\% lower femur density in rats after 3 months of alcohol treatment (alcohol in the drinking tap water, $7.6 \mathrm{~g} / \mathrm{kg}$ ) (Broulik et al., 2010). Therefore, this alcohol treatment can induce an osteopenia similar to those observed with a liquid diet or with tap water containing ethanol in animal models.

In humans, the BMD is generally decreased by $1-10 \%$, depending on the region analyzed (Table 3). Laitinen et al. reported 1\% lower BMD at the vertebrae (Laitinen et al., 1992). Alvisa-Negrin et al. reported $8 \%$ lower BMD in male and female alcoholic subjects (Alvisa-Negrin et al., 2009).

In the present study, microarchitectural parameters were also drastically affected after 11 weeks of exposure to ethanol vapor. The bone volume fraction (BV/TV) was decreased by $37 \%$ in the ethanol group compared to the control group and the trabecular number (Tb.N) was decreased by $37 \%$ while the trabecular spacing was increased by $82 \%$. These results are consistent with the literature. Our team previously reported decreases of $25 \%$ of the BV/TV with a solution containing 35\% ethanol v/v in male Wistar rats (Maurel et al., 2011b). Maddalozzo et al. also reported decreases of $22 \%$ of the BV/TV, $25 \%$ of $\mathrm{Tb} . \mathrm{N}$ and an increase of $44 \%$ of the Tb.Sp, following 3 months of treatment with $35 \%$ ethanol liquid diet in 4 week-old male Sprague-Dawley rats (Maddalozzo et al., 2009). In a study by Sampson et al., the BV/TV was decreased by $46 \%$, the Tb.N by $43 \%$ and the Tb.Sp was increased by $119 \%$ following 8 weeks of ethanol liquid diet (35\% of the calories) in 4 week-old female 
Sprague-Dawley rats compared to pair-fed controls (Sampson et al., 1997). Our results are close to the changes observed by Sampson et al. (1997) in young female rats. The changes are a little lower but our rats are older and as shown by the study by Sampson (Sampson et al., 1998), the effects of alcohol tend to be lower on some parameters in older animals. In comparison with animal models with similar BALs, the effects of this protocol on BV/TV and Tb.N are close. However, we did not observe an effect of alcohol on trabecular thickness (Tb.Th) with this technique, as for the study by Sampson et al. with similar BAL (Sampson, 1998).

There are very few papers assessing bone microarchitecture after chronic alcohol consumption in men and women (Maurel et al., 2012). In human subjects, with consumption comparable to $\mathrm{BAL}$ of $200 \mathrm{mg} / \mathrm{dl}$ in animals, the trabecular bone volume analyzed by histomorphometry is lower by 26 to $36 \%$ (Table 3 ). Then the data found in our model are in the same range, and the BV/TV decrease is very close to the data reported by De Vernejoul et al. (De Vernejoul et al., 1983). We observed lower trabecular number (Tb.N), as observed before in post menopausal women and pre menopausal women with osteoporosis (Dufresne et al., 2003; Liu et al., 2010).

This ethanol vapor exposure model allows easily achieving high BALs, the BALs can be controlled easily and bone pathology as osteopenia can be induced similarly to other models. In conclusion, the chronic and intermittent exposure to alcohol vapor seems to be a good model to study the alcohol-induced osteopenia in the rat.

Acknowledgements. This study was supported by the Conseil Régional de Picardie $\quad$ (CRP), the Inter-ministerial Mission for the fight against drugs and drug addiction (MiLDT)-National Institute of Health and Medical Research (INSERM)-Institute of Cancer (InCa) (Contracts 
A08095ES and A09119ES), Institut de France/Fondation NRJ "Biology of addiction". ESO is supported by a doctoral fellowship from the CRP. We thank Ludovic Didier for his technical assistance. 


\section{REFERENCES}

Alvisa-Negrin J, Gonzalez-Reimers E, Santolaria-Fernandez F, Garcia-Valdecasas-Campelo E, Valls MR, Pelazas-Gonzalez R, Duran-Castellon MC, de Los Angeles Gomez-Rodriguez M (2009) Osteopenia in alcoholics: effect of alcohol abstinence. Alcohol Alcohol 44:468475.

Bonnet N, Benhamou CL, Brunet-Imbault B, Arlettaz A, Horcajada MN, Richard O, Vico L, Collomp K, Courteix D (2005) Severe bone alterations under beta2 agonist treatments: bone mass, microarchitecture and strength analyses in female rats. Bone 37:622-633.

Bonnet N, Laroche N, Vico L, Dolleans E, Benhamou CL, Courteix D (2006) Dose effects of propranolol on cancellous and cortical bone in ovariectomized adult rats. J Pharmacol Exp Ther 318:1118-1127.

Broulik PD, Vondrova J, Ruzicka P, Sedlacek R, Zima T (2010) The effect of chronic alcohol administration on bone mineral content and bone strength in male rats. Physiol Res 59:599604.

Callaci JJ, Himes R, Lauing K, Wezeman FH, Brownson K (2009) Binge alcohol-induced bone damage is accompanied by differential expression of bone remodeling-related genes in rat vertebral bone. Calcif Tissue Int 84:474-484. 
D'Souza El-Guindy NB, Kovacs EJ, De Witte P, Spies C, Littleton JM, de Villiers WJ, Lott AJ, Plackett TP, Lanzke N, Meadows GG (2010) Laboratory models available to study alcohol-induced organ damage and immune variations: choosing the appropriate model. Alcohol Clin Exp Res 34:1489-1511.

De Vernejoul MC, Bielakoff J, Herve M, Gueris J, Hott M, Modrowski D, Kuntz D, Miravet L, Ryckewaert A (1983) Evidence for defective osteoblastic function. A role for alcohol and tobacco consumption in osteoporosis in middle-aged men. Clin Orthop Relat Res (179):107115.

Dufresne TE, Chmielewski PA, Manhart MD, Johnson TD, Borah B (2003) Risedronate preserves bone architecture in early postmenopausal women in 1 year as measured by threedimensional microcomputed tomography. Calcif Tissue Int 73:423-432.

Ebeling PR (1998) Osteoporosis in men. New insights into aetiology, pathogenesis, prevention and management. Drugs Aging 13:421-434.

Gonzalez-Calvin JL, Garcia-Sanchez A, Bellot V, Munoz-Torres M, Raya-Alvarez E, Salvatierra-Rios D (1993) Mineral metabolism, osteoblastic function and bone mass in chronic alcoholism. Alcohol Alcohol 28:571-579. 
Hogan HA, Groves JA, Sampson HW (1999) Long-term alcohol consumption in the rat affects femur cross-sectional geometry and bone tissue material properties. Alcohol Clin Exp Res 23:1825-1833.

Hogan HA, Sampson HW, Cashier E, Ledoux N (1997) Alcohol consumption by young actively growing rats: a study of cortical bone histomorphometry and mechanical properties. Alcohol Clin Exp Res 21:809-816.

Laitinen K, Lamberg-Allardt C, Tunninen R, Harkonen M, Valimaki M (1992) Bone mineral density and abstention-induced changes in bone and mineral metabolism in noncirrhotic male alcoholics. Am J Med 93:642-650.

Lespessailles E, Jaffre C, Beaupied H, Nanyan P, Dolleans E, Benhamou CL, Courteix D (2009) Does exercise modify the effects of zoledronic acid on bone mass, microarchitecture, biomechanics, and turnover in ovariectomized rats? Calcif Tissue Int 85:146-157.

Lieber CS, DeCarli LM, Sorrell MF (1989) Experimental methods of ethanol administration. Hepatology 10:501-510.

Liu XS, Cohen A, Shane E, Stein E, Rogers H, Kokolus SL, Yin PT, McMahon DJ, Lappe JM, Recker RR, Guo XE (2010) Individual trabeculae segmentation (ITS)-based morphological analysis of high-resolution peripheral quantitative computed tomography 
images detects abnormal trabecular plate and rod microarchitecture in premenopausal women with idiopathic osteoporosis. J Bone Miner Res 25:1496-1505.

Maddalozzo GF, Turner RT, Edwards CH, Howe KS, Widrick JJ, Rosen CJ, Iwaniec UT (2009) Alcohol alters whole body composition, inhibits bone formation, and increases bone marrow adiposity in rats. Osteoporos Int 20:1529-1538.

Maurel DB, Boisseau N, Benhamou CL, Jaffre C (2011a) Cortical bone is more sensitive to alcohol dose effects than trabecular bone in the rat. Joint Bone Spine Nov 29. [Epub ahead of print].

Maurel DB, Boisseau N, Benhamou CL, Jaffre C (2012) Alcohol and bone: review of dose effects and mechanisms. Osteoporos Int 23:1-16.

Maurel DB, Jaffre C, Rochefort GY, Aveline PC, Boisseau N, Uzbekov R, Gosset D, Pichon C, Fazzalari NL, Pallu S, Benhamou CL (2011b) Low bone accrual is associated with osteocyte apoptosis in alcohol-induced osteopenia. Bone 49:543-552.

Naassila M, Beauge FJ, Sebire N, Daoust M (2000) Intracerebroventricular injection of antisense oligos to nNOS decreases rat ethanol intake. Pharmacol Biochem Behav 67:629636. 
O'Dell LE, Roberts AJ, Smith RT, Koob GF (2004) Enhanced alcohol self-administration after intermittent versus continuous alcohol vapor exposure. Alcohol Clin Exp Res 28:16761682.

Peris P, Guanabens N, Monegal A, Suris X, Alvarez L, Martinez de Osaba MJ, Hernandez MV, Munoz-Gomez J (1995) Aetiology and presenting symptoms in male osteoporosis. Br J Rheumatol 34:936-941.

Rimondini R, Arlinde C, Sommer W, Heilig M (2002) Long-lasting increase in voluntary ethanol consumption and transcriptional regulation in the rat brain after intermittent exposure to alcohol. Faseb J 16:27-35.

Roberts AJ, Heyser CJ, Cole M, Griffin P, Koob GF (2000) Excessive ethanol drinking following a history of dependence: animal model of allostasis. Neuropsychopharmacology 22:581-594.

Sampson HW (1998) Effect of alcohol consumption on adult and aged bone: a histomorphometric study of the rat animal model. Alcohol Clin Exp Res 22:2029-2034.

Sampson HW, Chaffin C, Lange J, DeFee B, 2nd (1997) Alcohol consumption by young actively growing rats: a histomorphometric study of cancellous bone. Alcohol Clin Exp Res 21:352-359. 
Sampson HW, Hebert VA, Booe HL, Champney TH (1998) Effect of alcohol consumption on adult and aged bone: composition, morphology, and hormone levels of a rat animal model. Alcohol Clin Exp Res 22:1746-1753.

Simon O'Brien E, Legastelois R, Houchi H, Vilpoux C, Alaux-Cantin S, Pierrefiche O, Andre E, Naassila M (2011) Fluoxetine, desipramine, and the dual antidepressant milnacipran reduce alcohol self-administration and/or relapse in dependent rats. Neuropsychopharmacology 36:1518-1530.

Torricelli P, Fini M, Giavaresi G, Borsari V, Rimondini L, Rimondini R, Carrassi A, Giardino R (2007) Intermittent exposure to ethanol vapor affects osteoblast behaviour more severely than estrogen deficiency does in vitro study on rat osteoblasts. Toxicology 237:168-176.

Turner RT (2000) Skeletal response to alcohol. Alcohol Clin Exp Res 24:1693-1701.

Turner RT, Kidder LS, Kennedy A, Evans GL, Sibonga JD (2001) Moderate alcohol consumption suppresses bone turnover in adult female rats. J Bone Miner Res 16:589-594.

Valdez GR, Roberts AJ, Chan K, Davis H, Brennan M, Zorrilla EP, Koob GF (2002) Increased ethanol self-administration and anxiety-like behavior during acute ethanol withdrawal and protracted abstinence: regulation by corticotropin-releasing factor. Alcohol Clin Exp Res 26:1494-1501. 


\section{Figure legend}

Figure 1: $3 \mathrm{D}$ reconstruction of the trabecular bone of the femur metaphysis in Control (C) and Ethanol (E) groups, after micro-computed tomography acquisition.
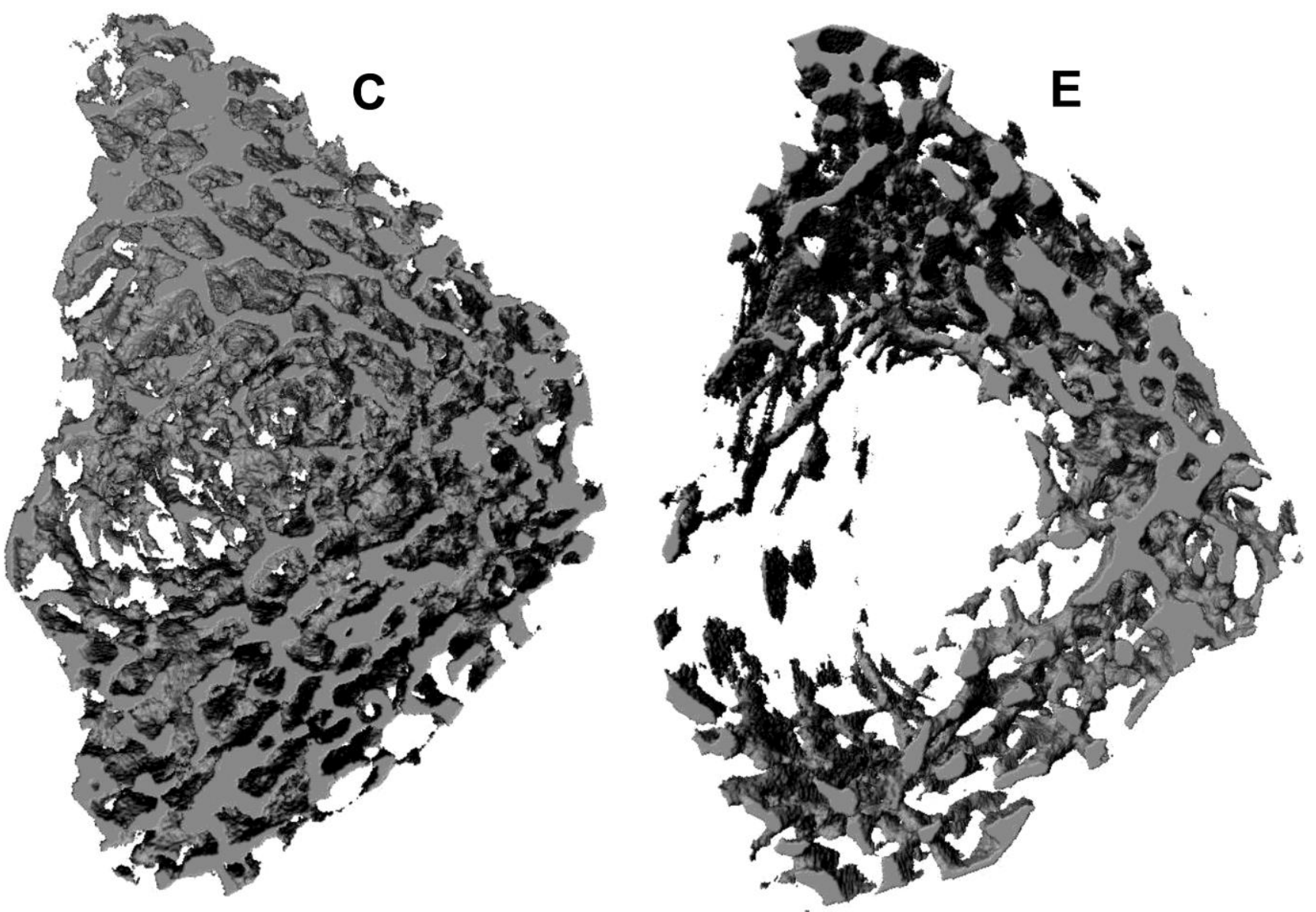


\begin{tabular}{|c|c|c|c|}
\hline & Controls & Ethanol & p \\
\hline Left femur BMC (g) & $0,53 \pm 0,03$ & $0,50 \pm 0,03$ & NS \\
\hline Left femur BMD (g/cm2) & $0,250 \pm 0,011$ & $0,234 \pm 0,010$ & 0,025 \\
\hline Right femur BMC (g) & $0,53 \pm 0,03$ & $0,50 \pm 0,04$ & NS \\
\hline Right femur BMD (g/cm²) & $0,255 \pm 0,012$ & $0,238 \pm 0,009$ & 0,037 \\
\hline Left tibia BMC (g) & $0,35 \pm 0,03$ & $0,36 \pm 0,04$ & NS \\
\hline Left tibia BMD ( $\left.\mathrm{g} / \mathrm{cm}^{2}\right)$ & $0,214 \pm 0,007$ & $0,204 \pm 0,007$ & 0,025 \\
\hline Right tibia BMC (g) & $0,36 \pm 0,04$ & $0,33 \pm 0,05$ & NS \\
\hline Right tibia BMD (g/cm²) & $0,211 \pm 0,012$ & $0,195 \pm 0,016$ & 0,054 \\
\hline
\end{tabular}

Table 1 


\begin{tabular}{cccc}
\hline & Controls & Ethanol & $\mathbf{p}$ \\
\hline BV/TV $(\%)$ & $20,93 \pm 4,78$ & $13,17 \pm 4,92$ & 0,025 \\
Tb.Th $(\mathbf{m m})$ & $0,096 \pm 0,002$ & $0,096 \pm 0,009$ & NS \\
Tb.N $(\mathbf{1 / m m})$ & $2,18 \pm 0,48$ & $1,37 \pm 0,50$ & 0,016 \\
Tb.Sp $(\mathbf{m m})$ & $0,34 \pm 0,13$ & $0,62 \pm 0,34$ & 0,037 \\
DA & $2,25 \pm 0,21$ & $2,23 \pm 0,34$ & NS \\
\hline
\end{tabular}

Table 2 


\begin{tabular}{|c|c|c|c|c|c|}
\hline Model & Alcohol consumption & Age & Sexe & Effects on bone tissue & Study \\
\hline A6 & $\sim 204 \mathrm{~g} / \mathrm{d}$ for 28 years & $\sim 50$ years & $\mathrm{F} / \mathrm{M}$ & $\begin{array}{l}\text { Subtotal BMD : }-8 \% \\
\text { Leg BMD: }-10 \% \text { (DXA) }\end{array}$ & Alvisa- Negrin et al. 2009 \\
\hline 2. & $\sim 180 \mathrm{~g} / \mathrm{d}$ & $35-50$ years & M & $\begin{array}{l}\text { Trab. Bone vol: }-36 \% \\
\text { Mean trab. Thickness: }-18 \% \\
\text { (histomorphometry) }\end{array}$ & De Vernejoul et al. 1983 \\
\hline$\sum_{10}^{80}$ & $\sim 223 \mathrm{~g} / \mathrm{d}$ for $6-30$ years & $31-61$ years & M & $\begin{array}{l}\text { BMD: - } 1 \% \text { (DXA) } \\
\text { lower when adjustment for body weight } \\
\text { and age }\end{array}$ & Laitimen et al. 1992 \\
\hline$\sum_{i=1}$ & $170-210 \mathrm{~g} / \mathrm{d}$ for $11-15$ years & $27-50$ years & $M / F$ & $\begin{array}{l}\text { Low BMD in lumbar spine, femoral neck, } \\
\text { total hip: } 24 \% \text { of males (DXA) } \\
\text { Intertrochanteric region: Iow BMD: } 5 \% \text { females }\end{array}$ & Malik et al. 2009 \\
\hline in & $\sim 170 \mathrm{~g} / \mathrm{d}$ for $7-26$ years & $\sim 41$ years & M & $\begin{array}{l}\text { BVITV: }-26 \% \\
\text { Tb.Th: }-33 \% \\
\text { Tb.N: NS } \\
\text { Tb.Sp: }+4 \% \text { (histomorphometry) }\end{array}$ & Schnitzler et al. 2010 \\
\hline
\end{tabular}

Table 3 


\section{Table legends}

Table 1: Bone mineral content (BMC) and bone mineral density (BMD) of the right and left femur and tibia, assessed by DXA after the sacrifice.

Table 2: Microarchitectural parameters of the trabecular bone in the femur, assessed ex vivo by microCT.

Table 3: Bone mineral density and microarchitecural changes in human studies of alcohol abuse. 